\title{
An Infant Ventilator Technique for Resistive Unloading during Spontaneous Breathing. Results in a Rabbit Model of Airway Obstruction ${ }^{1}$
}

\author{
ANDREAS SCHULZE, PETER SCHALLER, BERND GEHRHARDT, HANS-JÜRGEN MÄDLER, \\ AND DIETER GMYREK \\ Children's Hospital, Department of Neonatology, and the Institute of Biomedical Engineering, Medical Academy \\ "Carl Gustav Carus," Dresden, East Germany
}

\begin{abstract}
The combined system of ventilator circuit, endotracheal tube, and lung commonly imposes a resistive load on spontaneous breathing efforts. It is possible to compensate for this positive resistance by a device generating a "negative ventilator resistance" (NVR), i.e. delivering a positive pressure during inspiration and a negative pressure during expiration in constant proportion to the instantaneous flow of the spontaneous breathing. The concept of NVR implies that there must not be any phase lag between flow and pressure signals. In eight anesthetized, intubated, spontaneously breathing rabbits (mean body wt $3570 \mathrm{~g}$, range $2900-4600 \mathrm{~g}$ ), challenged either by aerosolized histamine or an extrapulmonary resistive load, lung mechanical data were calculated from esophageal pressure and flow signals. Each animal served as its own control with and without NVR. In a total of 39 experiments, NVR was applied in amounts between 1 and $15 \mathrm{kPa} \cdot \mathrm{s} / \mathrm{L}$. During both types of additional resistive load, NVR immediately reduced the resistive work of breathing. There was a strong linear correlation between the amount of NVR applied and the decrease in total resistance, where the total resistance equals the resistive load on the animal's respiratory muscles (sum of the resistances of all components of the combined respirator-lung system): $r=0.93, p<0.001$. The relationship between $\mathrm{NVR}$ and the drop in resistive work per $\mathrm{mL}$ of tidal volume was similar: $r=0.85, p<$ 0.001 . Throughout the experiments, NVR operated in perfect synchronization with the animal's spontaneous breathing activity.(28: 79-82, 1990)
\end{abstract}

\section{Abbreviations}

CPAP, continuous positive airway pressure

NVR, negative ventilator resistance

$P_{\text {es, }}$ esophageal pressure

$P_{m}$, pressure at the mouthpiece level

$\mathbf{R}_{\text {ext }}$, extrapulmonary resistive load

$\dot{\mathbf{V}}$, flow

Previously, one of us (P.S.) described a device to reduce the btal resistance of the combined ventilator-endotracheal tubeatient system in infants using a principle called NVR (1-3).

Commonly, a ventilator imposes a resistive load (i.e. a positive

Received October 25, 1989; accepted March 10, 1990

Correspondence and reprint requests: Dr. sc. med. A. Schulze, Medical Academy arl Gustav Carus," Children's Hospital, Dept. Neonatology, Fetscherstr. 74, resden, East Germany.

'Presented in part at the Annual Meeting of the European Society for Pediatric esearch. Oslo. Norway 1988. resistance) on the patient's spontaneous breathing efforts. That is, the pressure at the endotracheal tube's connector $\left(\mathrm{P}_{\mathrm{m}}\right)$ drops during inspiration and rises during expiration as a function of $\dot{V}$. If a ventilator's resistance equals 0 , there is no upward or downward deviation in $\mathrm{P}_{\mathrm{m}}$ during spontaneous breathing. Therefore, with NVR, the apparatus delivers a positive $\mathrm{P}_{m}$ during inspiration and a negative $\mathrm{P}_{\mathrm{m}}$ during expiration in a constant proportion to $\dot{\mathrm{V}}$. This proportion, $\mathrm{P}_{\mathrm{m}} / \dot{\mathrm{V}}$, has units of resistance and determines the degree of resistive unloading of spontaneous breathing.

The aim of our study was to test the applicability of NVR in reducing the resistive work of breathing in an animal model of airway obstruction.

\section{MATERIALS AND METHODS}

Description of the ventilator. The ventilator (4) uses a constant flow of $12 \mathrm{~L} / \mathrm{min}$ of humidified and warmed gas, which enters a venturi system (Fig. 1). The main outlet of this system is partly (but never totally) obstructed by a metal plate moved by a bobbin. The distance of the plate from the main outlet determines the magnitude and direction of the $\dot{V}$ through the lateral outlet of the venturi system. In other words, the jet flow within this system enables the unit to provide positive and negative pressures at the lateral outlet, where the line to the patient is inserted. This line consists of narrow tubes and incorporates a miniaturized pneumatometer, which has been described elsewhere $(5,6)$. A $P_{m}$ transducer is built in next to the patient. Each signal is fed into its own controller, where it is compared with reference signals provided by a microcomputer. The bobbin receives the amplified output (error signal) of either the $\mathrm{P}_{\mathrm{m}}$ or the $\dot{V}$ controller. In the CPAP mode for spontaneous breathing, the ventilator uses only the pressure feedback loop to maintain a constant $\mathrm{P}_{\mathrm{m}}$. To generate NVR, the $\dot{\mathrm{V}}$ signal is also imposed on the error signal of the $\mathrm{P}_{\mathrm{m}}$ controller in such a manner that an inspiratory flow increases $\mathrm{P}_{\mathrm{m}}$, whereas an expiratory flow decreases $P_{m}$. There is no phase lag between $P_{m}$ and $\dot{V}$. An adjustable amplifier of the $\dot{V}$ signal allows selection of the desired amount of NVR. The additional dead space between the venturi system and the patient amounts to $2 \mathrm{~mL}$.

Animal model. Eight healthy adult rabbits (mean body wt 3570 $\mathrm{g}$, range $2900-4600 \mathrm{~g}$ ) were anesthetized i.v. by a bolus of sodium pentobarbital $(30 \mathrm{mg} / \mathrm{kg})$. They were intubated with cuffed endotracheal tubes (inner diameter $4 \mathrm{~mm}$ ). Anesthesia was maintained by supplemental boluses of pentobarbital. We attempted to keep the anesthetic level just at surgical anesthesia, and not more, to give as little depressing impact on spontaneous breathing efforts as possible. After termination of the anesthesia, all animals were allowed to recover and were not restudied.

Study protocol. All rabbits were exposed to NVR in three separate sets of experiments: 1 ) without additional resistive load, 
2) with an additional $R_{\text {ext }}$, and 3) during histamine-induced intrapulmonary airway obstruction. Each animal served as its own control, with and without NVR. Measurements of respiratory mechanics were made just before and again 4 min after introduction of $\mathrm{R}_{\mathrm{ext}}$, or before and after histamine inhalation. NVR was instituted after these control measurements. Between 30 and 50 consecutive breathing cycles were recorded. Finally, NVR was withdrawn and control measurements were repeated to prove the stability of the model. Up to 11 comparisons with and without NVR were performed on each animal.

$R_{\text {ext }}$ was imposed either by narrowing the endotracheal tube with a clamp or by inserting a wire mesh resistance between the endotracheal tube and the pneumatometer. At $3 \mathrm{~L} / \mathrm{min}$, the two resistors had resistances of 7 and $11 \mathrm{kPa} \cdot \mathrm{s} / \mathrm{L}$, respectively (nonlinearity $<10 \%$ between 0 and $5 \mathrm{~L} / \mathrm{min}$ ).

For histamine inhalation, aerosols were generated by an ultrasonic nebulizer (particle diameter between 0 and $10 \mu \mathrm{m}$ ). The animals inhaled concentrations of 50 or $100 \mathrm{mg}$ of histamine/ $\mathrm{mL}$ of $\mathrm{H}_{2} \mathrm{O}$ for 5 to 10 consecutive breaths according to the recommendations of Quan et al. (7).

Measurements of respiratory mechanics. A 5 French open-end polyethylene catheter was placed in the lower esophagus and positioned where the $\mathrm{P}_{\mathrm{es}}$ had the greatest amplitudes in spontaneous breathing. The catheter was saline-filled and continuously flushed to keep the system free of bubbles. It was attached directly to a pressure transducer (W 101, VEB Kombinat Meßgerätewerk Zwönitz, East Germany), which was placed at the estimated level of the tip of the catheter. The frequency response of the whole system was adequate to $25 \mathrm{~Hz}$. After inserting the esophageal catheter, we placed the animals in the right lateral position. An infant pneumotachograph $(5,6)$ coupled to a differential pressure transducer (cut-off frequency of the whole system, $29 \mathrm{~Hz}$ ) was attached to the endotracheal tube. This sensor's $\mathrm{V}$ signal and the $\mathrm{P}_{\mathrm{es}}$ signal were on-line digitized. Data were loaded at a rate of one data point per $20 \mathrm{~ms}$ into a microcomputer and displayed on-line as a function of time. This enabled the operator to inspect the data and to decide whether they were suitable for analysis and storage. Periods with esophageal peristalsis, artifacts due to mucus obstructions of catheter systems or tubes, and disturbances of the $\mathrm{P}_{\mathrm{es}}$ signal by cardiac movements were rejected. The microcomputer provided breath-by-breath calculations of respiratory frequency, tidal volume, total resistance $\left(R_{\text {tot }}\right)$, and resistive work of breathing. $\mathrm{R}_{\mathrm{tot}}$ was computed according to the following equation:

$$
R_{\mathrm{tot}}=\frac{\int_{t_{1}}^{t_{2}} \mathrm{P}_{\mathrm{es}} \cdot \dot{\mathrm{V}} \mathrm{dt}}{\int_{t_{1}}^{t_{2}}(\dot{\mathrm{V}})^{2} \mathrm{dt}}
$$

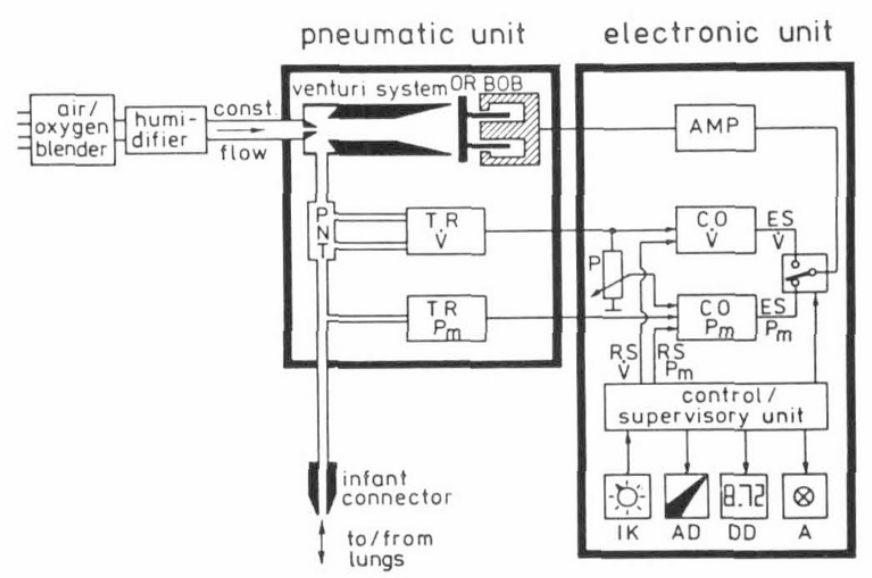

Fig. 1. General diagram of ventilator. PNT, pneumotachograph; TR, transducer; $\dot{V}$. flow; $P_{m}$, mouth pressure; $C O$, controller; $R S$, reference signal; $E S$, error signal; $A M P$, amplifier; $B O B$, bobbin; $O R$, variable outflow restriction; $P$, potentiometer; $I K$, input knobs; $A D$, analog display; $D D$, digital display: $A$, alarm. For further explanation, see text. where $t_{1}$ is the time at end expiration of one breath and $t_{2}$ is the time at end expiration of the following breath.

Full details of our devices to test lung function and their characteristics have been described elsewhere (8). The animals breathed via the respirator while on CPAP mode with the $\dot{V}$ sensor mounted between the endotracheal tube and the respirator's connector.

Criteria for acceptance of an experimental run. Experiments were accepted for evaluation if the signals of at least 10 consecutive breathing cycles with and without NVR were suitable for computer calculation of lung mechanical data. A breathing cycle was excluded by the computer from evaluation if there was a difference of greater than $10 \%$ between initial inspiratory and end expiratory $\mathrm{P}_{\mathrm{es}}$ or between inspiratory and expiratory volume. Furthermore, a difference in baseline resistance before and after NVR greater than $1 \mathrm{kPa} \cdot \mathrm{s} / \mathrm{L}$ was a criterion for rejection of a histamine experiment.

Statistical analysis. Data are expressed as mean \pm 1 SD. Linear regression analysis was performed using the least squares method to obtain the best fitting lines in Figures 6 and 7.

\section{RESULTS}

Figure 2 presents hard copies of original tracings. There is no departure of the $\mathrm{P}_{\mathrm{m}}$ signal from 0 line with 0 ventilator resistance (Fig. 2A). With NVR in function (Fig. $2 B$ ), $\mathrm{P}_{\mathrm{m}}$ is positive during inspiration and negative during expiration. The relationship between the amplitudes of the $\mathrm{P}_{\mathrm{m}}$ signal and the $\dot{\mathrm{V}}$ signal is constant. $\mathrm{P}_{\mathrm{m}}$ follows $\dot{\mathrm{V}}$ without any phase lag. It must be emphasized that $\mathrm{P}_{\mathrm{m}}$ reaches 0 (or any preset baseline CPAP level) when $\dot{\mathrm{V}}$ crosses $0 . \mathrm{P}_{\mathrm{es}}$ amplitudes are reduced with NVR. In this experiment (Fig. 2), CPAP was 0 . These same effects of NVR were achieved at any desired CPAP.

Figure 3 demonstrates plots of $\mathrm{P}_{\mathrm{cs}}$ against volume (integral of $\dot{V})$. The areas surrounded by the $\mathrm{P}_{\mathrm{es}}$-volume loops represent the resistive work of breathing. As a result of introduction and increase of NVR, the loops became narrower (middle and right panel), i.e. the animal's resistive work of breathing was reduced.

Figure 4 depicts a single experiment. The initially applied $R_{\text {ext }}$ was compensated for by means of NVR. There was a slight concomitant increase in the respiratory rate. Tidal volume did not change.

NVR was equally effective in histamine-induced airway obstruction as shown in Figure 5. Neither the respiratory rate nor

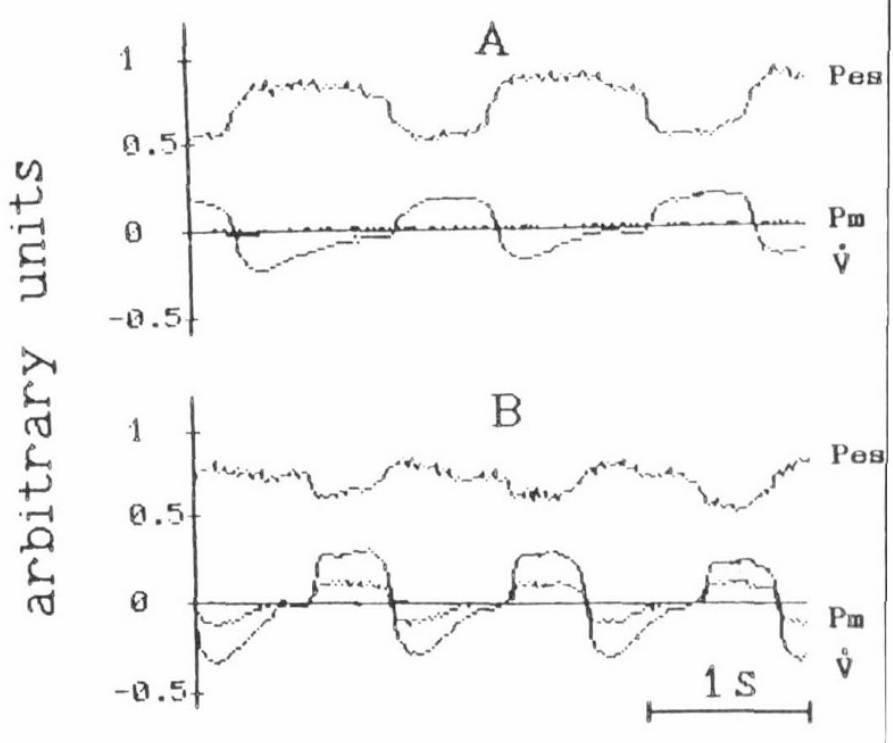

Fig. 2. Original tracings of $P_{c}, P_{m}$, and air flow $(\dot{V})$ during spontaneous breathing with 0 ventilator resistance $(A)$ and with negative ventilator resistance $(B)$ under steady state conditions. Note the decrease in $P_{e s}$ swing with negative ventilator resistance. 


\begin{tabular}{rlrrr|}
$R_{\text {ext }}=$ & 7 & 7 & 7 & $\mathrm{kPa} \cdot \mathrm{s}$ \\
$R_{\mathrm{V}}=$ & 0 & -7 & -10 & $\frac{\mathrm{l}}{\mathrm{ml}}$ \\
\hline
\end{tabular}
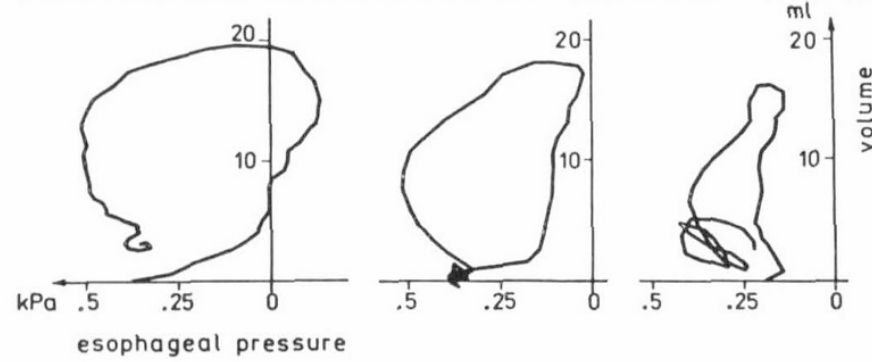

Fig. 3. $\mathrm{P}_{\mathrm{es}}$-volume-loops with a strong $R_{e x t}$ (left panel) and after addition of two different amounts of negative ventilator resistance $\left(R_{V}\right)$ (middle, right panels).

\begin{tabular}{|lrrrrr|}
\hline \multicolumn{2}{|c|}{ Wres $_{5.9}^{37.2}$} & 35.5 & 31.8 & 27.1 & $9.5 \mathrm{~mJ}$ \\
\hline $\mathrm{V}_{\mathrm{T}}$ & $\begin{array}{r}29.0 \\
29.8\end{array}$ & 30.7 & 32.9 & 32.4 & $28.7 \mathrm{ml}$ \\
\hline
\end{tabular}

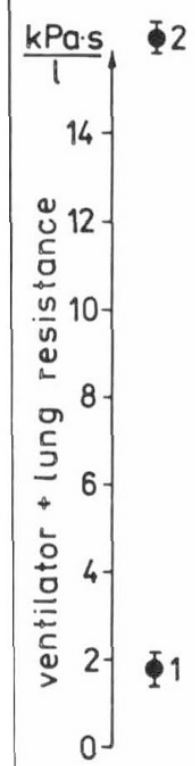

\section{$\Phi 5$}

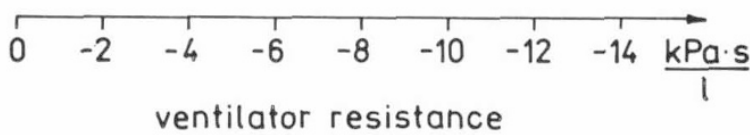

Fig. 4. Representative experimental run with an $\mathrm{R}_{\mathrm{ext}}$ inserted between points 1 and 2. The numbers adjacent to the points indicate the sequence of the experiment. Results are mean $\pm \mathrm{SD}$ of 10 to 50 breathing cycles. $V_{T}$, tidal volume; $W_{r e s}$, resistive work of breathing.

the tidal volume was altered significantly until NVR approximated the amount of the animal's lung resistance. Beyond this borderline, there was a sharp increase in respiratory rate and drop in tidal volume.

Figure 6 summarizes all of the experimental runs irrespective of the kind of resistive load used. There is a significant linear relationship between the level of NVR applied and the resultant decrease in total resistance. Respiratory muscles' work has to overcome this total resistance, which is the sum of the lung's and ventilator's resistances.

Correspondingly, there is a strong correlation between the NVR and the drop in resistive work, which was expressed as $\mathrm{mJ} /$ $\mathrm{mL}$ of tidal volume (Fig. 7).
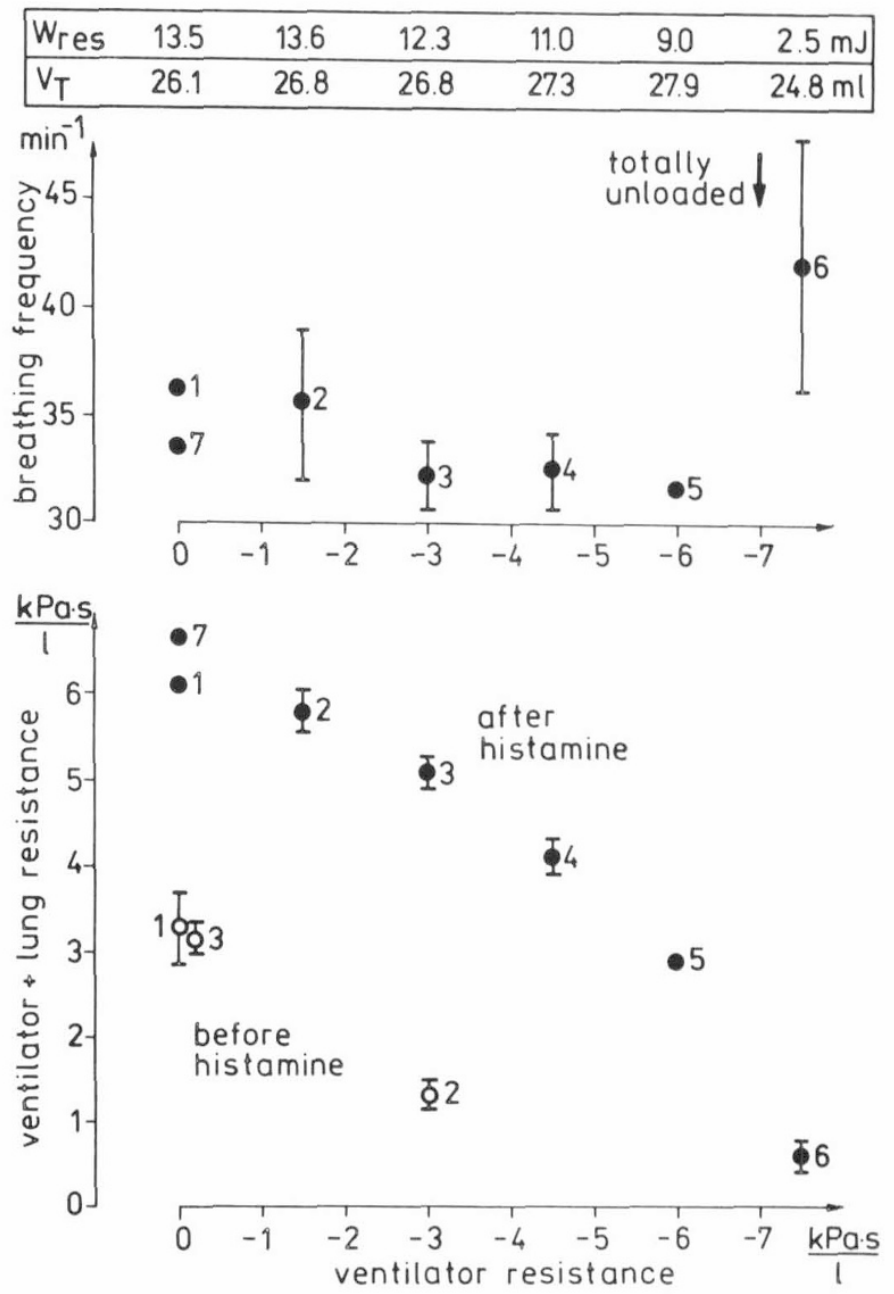

Fig. 5. Representative experimental run before histamine challenge (open circles) and thereafter (solid circles). The numbers adjacent to the points indicate the sequence of the experiment. There was practically no variability of the parameters measured during the periods 1,5 , and 7 . $V_{T}$, tidal volume; $W_{\text {res }}$, resistive work of breathing.

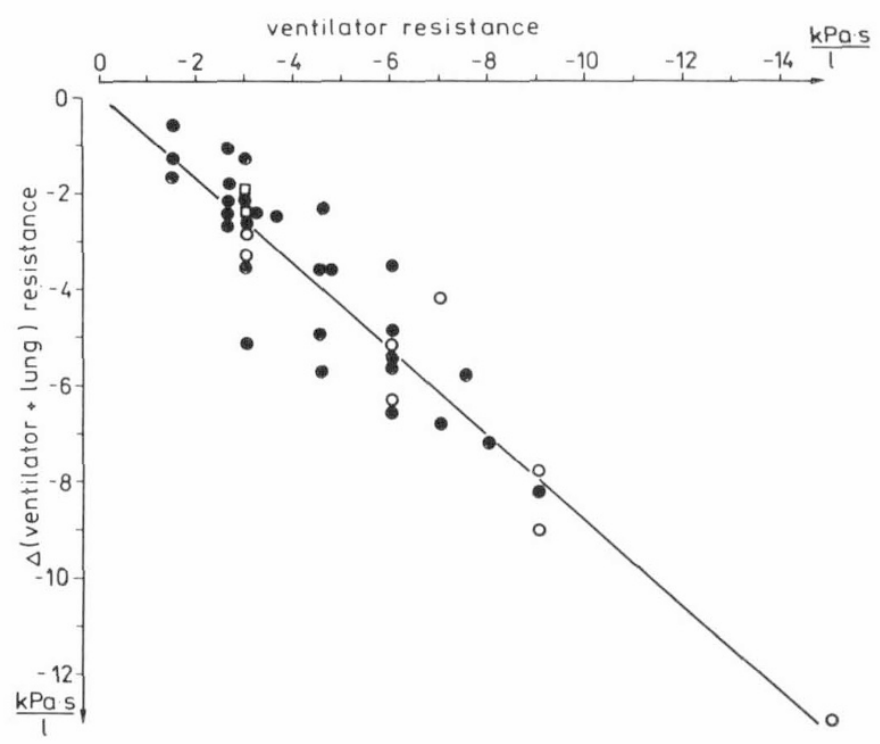

Fig. 6. Relationship between the amount of negative ventilator resistance used and the resultant drop in total resistance. Each point represents a single trial. Solid symbols, histamine-induced airway obstruction; open circles, $\mathrm{R}_{\text {ext }}$; open squares, unobstructed airways (i.e. only the natural resistive load). $r=0.93(n=39, p<0.001)$. 


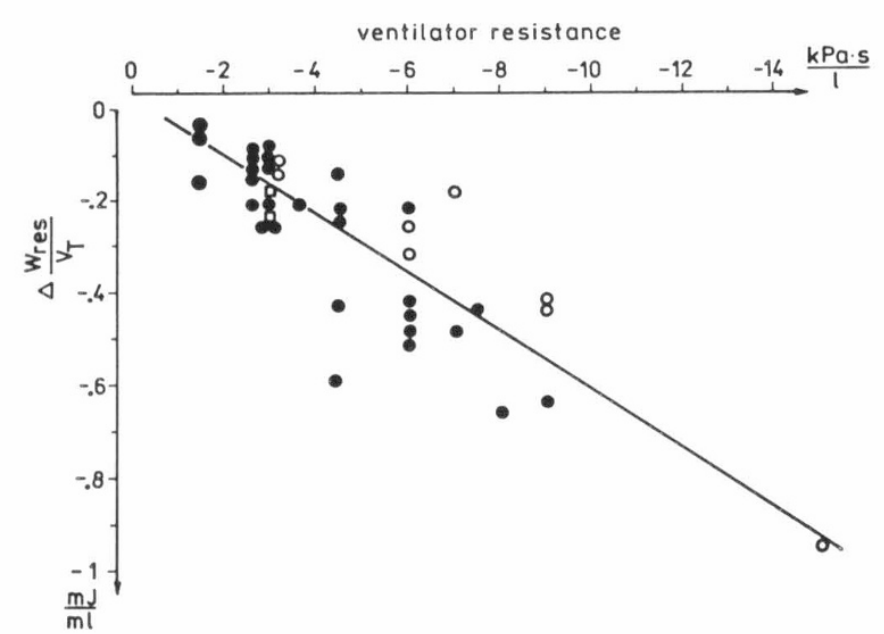

Fig. 7. Relationship between the amount of ventilator resistance used and the drop in resistive work ( $\left.W_{r e s}\right)$ per $\mathrm{mL}$ of tidal volume $\left(V_{T}\right)$. Each point represents a single trial. Solid symbols, histamine-induced airway obstruction; open circles, extrapulmonary resistive load; open squares, unobstructed airways. $r=0.85(n=39, p<0.001)$.

\section{DISCUSSION}

Even on the most recently developed ventilator systems, the work of spontaneous breathing was found to be elevated (9). Using a new conception for an infant ventilator system, we have shown in this study that a NVR effectively reduces a resistive load on spontaneous breathing irrespective of the load's local position along the airway.

To our knowledge, only Younes et al. (10) have constructed an apparatus producing inspiratory and expiratory resistive unloading with the magnitude of unloading being continuously adjustable. Their device was developed primarily for studying the control of breathing in adults by altering the mechanical load of the respiratory system. Unlike our NVR concept, this apparatus was not designed for therapeutic intervention. It is a separate unit not integrated into a complex ventilator as one mode of other possible functions.

Poon et al. $(11,12)$ described a similar technique for resistive unloading. They used a modified servo-controlled ventilator to impose a positive-pressure wave form whose shape was steered by the instantaneous flow signal. However, this assistance was confined to inspiration. Our approach works during the whole breathing cycle.

In this context, it seems necessary to point out that NVR fundamentally differs from what is called "negative expiratory pressure ventilation." This kind of expiratory support is usually realized by a venturi system, which is mounted in the expiratory limb of the ventilator's circuit and which creates a constant subatmospheric pressure during the expiratory phase. As a result, functional residual capacity may be reduced. Against this, NVR operates at any desired CPAP level.

In conclusion, NVR proved useful in supporting spontaneous breathing mechanically and in perfect synchronization with the rabbits' intrinsic breathing rhythm. The valveless ventilator system described in this study was designed for use with infants. NVR should be helpful for compensating resistive loads, especially in premature babies with their narrow endotracheal tubes, their increased airway resistance with prolonged mechanical ventilation, and their high risk of respiratory muscle fatigue. It is our hope that particularly the infant with bronchopulmonary dysplasia might benefit from this approach of respiratory support.

Acknowledgments. The authors thank Prof. G. Sedin, Uppsala, Sweden, Prof. H. Versmold, Munich, West Germany, and Prof. F. Pohlandt, Ulm, West Germany, for their critical comments on the manuscript.

\section{REFERENCES}

1. Schaller P 1982 Patent "Beatmungsgerät" DD A 61 M 16/00:212186, Berlin, East Germany

2. Schaller P 1983 Patent "Beatmungsgerät" DD A 61 H 31/00:221364, Berlin. East Germany

3. Schaller P 1987 Ein Druck-Volumenstrom-Generator zur Erzeugung von Ventilationsmustern für die Säuglingsbeatmung. Dissertation B,Technische Universität Dresden

4. Schulze A, Schaller P, Gehrhardt B, Mädler HJ, Dinger J, Gmyrek D, Winkle U, Nitzsche H, Mehler HJ 1989 High frequency oscillatory and conventiona mechanical ventilation in experimental surfactant deficiency: a study using a new infant ventilator technique. Z Erkr Atmungsorgane 172:272-281

5. Schaller P, Mädler HJ, Schulze A, Böhme B, Leupold W 1985 Ein LamellenSpirorezeptor für die Pneumotachographie bei Frühgeborenen und Säuglingen. Z Klin Med 40:947-949

6. Schaller P, Mädler HJ, Schulze A, Gmyrek D 1989 Optimal design of a pneumotachograph head with respect to dead space and resistance. Pediatr Res 26:517(abstr)

7. Quan SF, Witten ML, Stevenson JL, Roseberry HR, Lemen RJ 1986 Variability of pulmonary responsiveness to aerosolized histamine in normal rabbits. Respiration 50:108-116

8. Mädler HJ, Gehrhardt B, Schaller P, Böhme B, Schulze A, Gmyrek D 1985 Mikrorechnergestützter Meßplatz zur Ermittlung atemmechanischer Parameter bei Früh- und Reifgeborenen. Kinderarztl Prax 53:113-117

9. Cox D. Tinloi SF, Farrimond JG 1988 Investigation of the spontaneous modes of breathing of different ventilators. Intensive Care Med 14:532-537

10. Younes M, Bilan D, Jung D, Kroker H 1987 An apparatus for altering the mechanical load of the respiratory system. J Appl Physiol 62:2491-2499

11. Poon CS, Ward SA 1986 A device to provide respiratory-mechanical unloading. IEEE Trans Biomed Eng 33:361-365

12. Poon CS, Ward SA, Whipp BJ 1987 Influence of inspiratory assistance on ventilatory control during moderate exercise. J Appl Physiol 62:551-560 